\title{
Research on Regional Economic Development of Anhui Province Based on Diffusion Effect
}

\author{
Ma Qiufang ${ }^{1}$ \\ ${ }^{1}$ Huainan Normal University, Huainan, Anhui, China
}

\begin{abstract}
In the development of regional economy, giving full play to the advantages of diffusion effect can effectively promote the overall development of regional economy and improve the quality and efficiency of economic development. Based on the development of regional economy in Anhui Province, this paper discusses in detail the mechanism of diffusion effect and the great role that diffusion effect plays in the economic development of Hefei economic circle and Wanjiang city belt.
\end{abstract}

\section{Introduction}

In recent years, Anhui Province has established a strong economic circle with Hefei City as the center, sharing resources, realizing the overall development of the economy, and constantly improving the economic environment of the Lancang urban belt, improving its economic development level, and narrowing the gap between urban and rural economic development.These measures have greatly exerted the regional economic diffusion effect, driving the surrounding areas with the center, driving the villages with the city, realizing sustained and steady economic progress, and promoting people's living standards.

\section{Overview of diffusion effects}

The diffusion effect plays a huge role in China's current economic and technological development. It mainly means that when the development of commercial trade and infrastructure in a central region is relatively fast, it will definitely drive the development of economic technology in its peripheral regions. All kinds of resources in the central area, such as talents, technology, and ideas, will continue to radiate outward, which will benefit neighboring areas. Diffusion effect also means through the continuous spread and sharing of resources in the central region, the economic level of the neighboring regions will be greatly improved, and the economic, technological and cultural differences between the central region and the surrounding regions will be gradually reduced and merged to form some large cities with developed economy.

\section{Analysis of the mechanism of diffusion effect}

\subsection{The first premise of diffusion effect is to form aggregation effect}

The occurrence of diffusion benefit mainly depends on the formation of aggregation effect. Generally, if a region has abundant resources, such as human resources, commercial resources, information resources, technology resources, and in terms of space conditions, it is relatively close to the surrounding environment. In the process of the continuous development of economy and technology and the continuous improvement of productivity in this area, it will have a diffusion effect on the surrounding areas, and will transfer advanced production technology and human resources to the surrounding areas, at the same time, the highly developed enterprises in the region will also spread to the surrounding areas, thus driving the economic development of the surrounding areas.At the same time, due to the strong development advantages of the region, it will also attract all kinds of resources from the surrounding areas, so as to achieve mutual benefit and promote each other's development. This is equivalent to the formation of the benefits of resource aggregation, conducive to the overall economic stability.

\subsection{The creation of a diffusion effect}

The diffusion effect is that the growth pole transfers the industry chain, or makes a clear division of the links in the industry chain, subcontracts some links in the chain to the surrounding areas, brings advanced technology and resources, and drives the development of the surrounding economy. Some scholars have carried on the brief analysis to it from the two aspects of the industrial connection impetus and the regional economy, the economic 
environment improvement.

\subsubsection{The emergence of industrial linkage-driven diffusion effect}

Industrial linkages include vertical linkages, horizontal linkages and complementary linkages. Vertical connection is the connection between the upper and lower links of the product production chain; horizontal connection is the connection between the various subdivisions of the same industry; complementary connection is the complementary connection between the products of the two related industries that complement each other in their product functions, these related industries will lead to the creation of a diffusion effect. When the center and the region are in the development stage, the demand for production factors is large, a large number of inputs to take into account transport costs, will produce locally. When the development of central areas gradually mature, will attract more industrial chain, influx, many competitors will inevitably cause factor prices rise, production costs rise. In order to gain a competitive advantage, manufacturers will shift their perspective to peripheral products and even reduce costs by moving production lines.

\subsubsection{The improvement of regional economic environment promotes the generation of diffusion effect}

The environment here includes not only natural geographical conditions, such as climate, soil, water sources, but also human and economic conditions, such as population, education, legal system, policy measures and so on. The optimization of environmental conditions can improve the regional soft power, attract the population to gather, promote the economic development, and promote the proliferation effect. From the spread degree of the diffusion effect, it is found that the region with complete infrastructure, reasonable industrial structure, abundant human resources has obvious diffusion effect, whereas the region with abundant resources has weak diffusion effect. From the analysis of the spatial direction of the diffusion effect, the regions with well-developed transportation lines can promote the economic development along the lines, and the diffusion effect is obvious, whereas the regions with less-developed transportation lines and longer distances have weaker diffusion effect.

\section{Diffusion effect of regional economy in Anhui Province}

The economic level of Anhui Province has been continuously improved in recent years, which has benefited from its economic construction and the effective use of the diffusion benefits of the regional economy. In the specific practice, Anhui province attaches great importance to the economic circle of Hefei, the provincial capital city, and constantly improves the economic development environment of the Lancang City Belt to promote the development of various industries. In addition, it actively participates in the Yangtze River Delta Economic Zone. This series of measures have fully exerted the effects of economic diffusion and effectively promoted the overall development of Anhui's economic level.

\subsection{The diffusion effect of Hefei Economic Circle}

Since 2009, hefei economic circle has been established for ten years. Resources are Shared among various cities, and enterprises continuously cooperate to explore technology and management. In a short time, the GDP of each city within the economic circle has been greatly increased.

\subsubsection{Hefei city as the core area to drive the economic development of other cities}

In 2008, Hefei's GDP was 278.76 billion yuan, short; In the past six years, Hefei's GDP has nearly tripled. In 2014, Hefei's GDP was 963.1 billion yuan. In 2009, Hefei had the highest GDP growth rate. In 2010, there was a slight decrease, not because the economic development was backward, but because the overall GDP base increased. According to the specific situation, the economic development of Hefei in recent years has basically maintained a growth rate of $16.7 \%$. With the growing economic circle in Anhui Province, Xuzhou and Huai'an joined in, expanding the scope of the Economic Circle. More development resources have been imported, and the factors that can drive the continuous economic growth have been increased. Then more effectively promoted the Anhui Province Economic Circle overall economy unceasing development progress. In addition, with the continuous development of the economic circle, the level of its development has gradually stabilized, adding more management and technical aspects, improving the quality of development, ensuring the balance between the efficiency and quality of economic development.

\subsubsection{The per capita income of residents in the economic circle increased gradually}

The stable development of the Hefei Economic Circle has improved the per capita income of people within the economic circle and promoted people's quality of life. According to relevant information, it can be learned that from the establishment of the economic circle in 2008 to the basic development of the economic circle in 2014, the per capita income of urban residents has basically doubled, with an average annual growth rate of $11.8 \%$, and the growth rate of rural residents is $12.9 \%$. Fortunately, the per capita income of some prefecture-level cities or counties is almost the same as that of Hefei, which makes the economic development gap between urban and rural areas gradually narrow. For example, Tongcheng in Anhui Province, in a short period of time, has the same per capita income as the prefecture-level cities within the economic circle, and because of its own resource advantages, it can 
effectively maintain the stability and continuity of experience. It should be noted that this does not mean that the per capita income of all regions within the economic circle is weak. On the contrary, according to the actual situation, there is still a large gap in the per capita income of urban and rural residents within the economic circle. Relevant units actively innovate, give full play to the diffusion effect of the regional economy, promote the progress of the neighboring rural experience with the improvement of the urban experience environment, and then realize the integrated development of urban and rural economy.

\subsection{The diffusion effect of the Lancang urban belt}

\subsubsection{The economic structure of Wanjiang city belt has been optimized}

The economic development level of the Yangtze river delta economic zone is relatively high, and its resources can radiate to most cities in the city belt of Anhui river. The city zone of Wanjiang accepts the industry input from the coastal big cities, meanwhile, it continuously optimizes its original industrial structure according to the specific situation, so as to promote the economic development. In 2017, the proportion of the three major industries in the city belt of Wanjiang was 10.73:53.20:36.07. However, the proportion of the industrial structure was greatly adjusted in just two years, and by 2019 , the proportion of the three major industries had become 9.21:58.48:32.31. It should be noted that the optimization and upgrading of the industrial structure is not only obvious among the three major industries, but also has been adjusted and optimized within the three major industries. The first is the adjustment of the secondary industry, in which the proportion of industry increased significantly. In 2009, the proportion was $85.1 \%$, but in 2014 , it increased by about $2 \%$, and it was still increasing.

\subsubsection{The industry of coastal area undertakes}

The reason why the Lancang Economic Belt was established is to fully exert the diffusion effect and benefit the developed economy of the coastal areas, and accept the input of some industries to adjust its own economic structure. In the specific practice, because each city in the Lancang Economic Belt has its own situation, there are different choices in undertaking the industry. For example, Hefei City, as a provincial capital, has sufficient advantages in all aspects of politics and economy, and should play a leading and promoting role in the development of the economy in Anhui Province. Therefore, Hefei City needs to undertake coastal economic industries. Pay attention to the following points: First, we must make full use of the Yangtze River waterway, and undertake as many industries as possible that meet the needs of our own economic development and people's needs and have good development prospects. Secondly, it is necessary to actively combine the various regions of Hefei City, according to the characteristics of different regions to distribute the industries undertaken, and try to make the development of cities and villages as simultaneous as possible. It should be noted that, according to the geographical situation of Anhui Province, the urban belt of Anhui River can also fully cooperate with the northern Anhui region when undertaking the industries of the Coastal Economic Zone, it can share resources, on the other hand, it can also promote the overall economic development of Anhui Province.

\subsection{An analysis of the effect of regional economy on Yangtze River Delta Economic Zone in Anhui Province}

As an important province in the central region of China, Anhui province, while carrying on and receiving the Yangtze River Delta Economic Zone industrial transfer, will also integrate into the Yangtze River Delta Economic Zone through cooperation in an all-round way, and bring into play its own characteristics and advantages, resulting in a proliferation effect, we will promote sound and rapid economic and social development in the Yangtze River Delta Economic Zone in the following two aspects.

\subsubsection{From the perspective of coordinated development of regional economy, it has a strong complementarity}

Although the Yangtze River Delta Economic Zone economy is well developed, regional integration is low, regional and regional linkages are not large, scientific and efficient, and the industrial development model is not yet mature. The convergence of regional industrial structure may further lead to industrial isomorphism. Shanghai, Jiangsu, Zhejiang and other three provinces, close to the geographical location of the city, industrial isomorphism problem is very significant, Jiangsu, Zhejiang industry similarity coefficient as high as $97 \%$. From this point of view, Anhui Province, joining the Yangtze River Delta Economic Zone, improving the industrial structure, in order to strengthen the regional, inter-city industrial complementarity, deepening the division of labor within the regional industrial chain have, promote the role, to a certain extent, but also can solve part of the Yangtze river delta, problem of industrial isomorphism.

\subsubsection{From the perspective of the long term development of the Yangtze River Delta Economic Zone, Anhui's regional economy has a good prospect for development}

Yangtze River Delta Economic Zone, Shanghai is the financial center, and Zhejiang Province is the province with the highest GDP. Anhui province, as a new member, makes use of abundant human and natural resources and draws lessons from the "Wild goose pattern"[7] , Anhui province not only needs to mechanically inherit the advantageous industries of other regions, but also needs to flexibly combine its own characteristics, develop their 
own industrial chain, increase innovation efforts, cultivate the basic, market conditions and technical conditions, forming "Late-development advantage.". Anhui province, can use the production scale expansion, the scale economy utilization as well as labor, the power price superiority, realizes the economic development and the industrial upgrading goal. At the same time, industrial upgrading in Anhui province, in turn, drives the growth of the Yangtze River Delta region, through a large number of market demand and good prospects for development, to promote the further development of the Yangtze River Delta Economic Zone.

\section{Suggestions to promote diffusion effect}

In the process of economic development in Anhui Province, we should continue to make use of the principle of diffusion effect and actively improve the economic environment of Hefei, the provincial capital. Second, it is necessary to strengthen the training of all kinds of new talents, give full play to the role of talents, actively introduce talents, and pay attention to the improvement of education level at all levels in Hefei. In addition, it is also necessary to build a green Hefei, protect the natural environment, and develop cultural industries with local characteristics. Only by constantly improving the economic environment of Hefei can the diffusion effect be effectively exerted to drive the economic development of the surrounding areas, attract the development factors of the surrounding areas, and realize the integrated development of urban and rural economy, so as to promote the rapid and stable development of Hefei economic circle and promote the economic level of Anhui province.

Strengthening the economic development of the Lancang urban belt. While undertaking the industries in the coastal economically developed regions, we must constantly proceed from our own actual conditions, on the one hand, choose the right industry to undertake, and on the other hand, actively adjust its industrial structure. To promote economic development. First of all, when using the diffusion effects of developed regions, it is necessary to have a sufficient strategic vision, and to select potential industries in the long-term interests, in order to continue to develop in the future and promote economic growth. Secondly, when the industry undertakes the transfer, in addition to the government's control, it must also fully consider the market's adjustment mechanism, use the market to select the industry, and control the distribution of the industrial chain.

Give full play to the regional resource advantages of Anhui Province, fully integrated into the construction and development of the Yangtze River Delta Economic Zone. Anhui province, as the backbone of the rise of the central region, has certain advantages in resources, while the Yangtze River Delta Economic Zone has advantages in $\mathrm{R}$ $\& \mathrm{D}$, communications, logistics, trade and so on. At the same time, both need to develop in an all-round way and inject more fresh blood into each other. As an important part of the economic development of the Yangtze River
Delta, the regional economy of Anhui province still needs rational industrial distribution, cooperation between upstream and downstream of complementary industrial chain, improvement of the utilization rate of production factors, innovation and technology, and common development.

\section{Conclusion}

Fully exerting the advantages of the diffusion effect is crucial for the long-term stable development of the regional economy. Anhui Province uses the Hefei Economic Circle and the Lancang City Belt model to take advantage of Hefei as a provincial capital and the resources of economically developed cities in the coastal areas. It has realized the economic development of the countryside driven by the center and the urbanization by the city, narrowing the gap between urban and rural economic levels, and promoting the steady development of the overall economy of Anhui Province.

\section{Acknowledgments}

This paper is one of the achievements of the key research project of humanities and social sciences in Anhui Province Research on the Optimization of Service Industry Structure in Resource-based Cities during the Transformation Period(SK2016A0856) in 2016.

\section{References}

1. Qi Ran, Pan Heping. Research on regional economic development of Anhui province based on diffusion effect[J]. Journal of Luoyang Institute of Science and Technology(Social Science Edition), 2017(1).

2. Shi Dongjian, Zhang Li. The agglomeration and diffusion effect of cities 应 $[\mathrm{J}]$. Commercial Research, 2006(5):142-144.

3. Sha Fei, Zhang Shijun. Research on Regional Economic Diffusion Effect Model[J]. Inner Mongolia Science Technology \& Economy, 2006(22):3-5.

4. Song Haiyan, Cui Yonghong, Ren Yanjun. Domestic technology and economic diffusion research review[J]. China Circulation Economy, 2011(1):8182. 